Proceedings of the Symposium K: "Complex Oxide Materials for New Technologies" of E-MRS Fall Meeting 2006, Warsaw, September 4-8, 2006

\title{
Magnetic Properties of Oxygen Deficient $\mathrm{Y}_{0.33} \mathrm{Sr}_{0.67} \mathrm{CoO}_{3-\delta}$
}

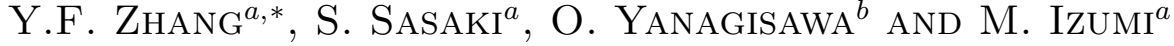 \\ ${ }^{a}$ Laboratory of Applied Physics, Tokyo University of Marine Science and \\ Technology, 2-1-6, Etchu-jima, Koto-ku, Tokyo 135-8533, Japan \\ ${ }^{b}$ Yuge National College of Maritime Technology, Ehime 794-2593, Japan
}

We studied magnetic properties of perovskite-type $\mathrm{Y}_{0.33} \mathrm{Sr}_{0.67} \mathrm{CoO}_{2.614}$ and $\mathrm{Y}_{0.33} \mathrm{Sr}_{0.67} \mathrm{CoO}_{2.707}$ prepared under different sintered temperatures at $1250^{\circ} \mathrm{C}$ and $1100^{\circ} \mathrm{C}$, respectively. A dc magnetization jump associated with a large thermal hysteresis around $180 \mathrm{~K}$ was found in $\mathrm{Y}_{0.33} \mathrm{Sr}_{0.67} \mathrm{CoO}_{2.614}$, which indicates a kind of magnetic memory effect. On the other hand, $\mathrm{Y}_{0.33} \mathrm{Sr}_{0.67} \mathrm{CoO}_{2.707}$ shows a larger magnetization with a small magnetization jump around $200 \mathrm{~K}$ and lower Curie temperature than those of $\mathrm{Y}_{0.33} \mathrm{Sr}_{0.67} \mathrm{CoO}_{2.614}$. Rich $\mathrm{Co}^{3+}$ ions in the low temperature sintered $\mathrm{Y}_{0.33} \mathrm{Sr}_{0.67} \mathrm{CoO}_{2.707}$ possibly introduce large magnetization and high magnetization jump temperature. This may be coming from a surface/volume effect of $\mathrm{Co}^{3+}$ ions appearing in the polycrystalline sample prepared at low temperature. The ferromagnetism resulted from the different surface/volume ratio contributes to a part of magnetization and may result in the change of the Curie temperature.

PACS numbers: 72.80.Ga, 75.60.-d, 75.70.Rf, 81.40.Rs

\section{Introduction}

The transition-metal oxides with perovskite-type structure $\mathrm{RE}_{1-x} \mathrm{Sr}_{x} \mathrm{CoO}_{3}$ ( $\mathrm{RE}$ is a rare-earth ion) have been extensively studied because of their rich physics and various spin states [1-3], i.e., low-spin state, intermediate-spin state, and high-spin state. The physical properties strongly depend on compositions as well as ionic and oxygen vacancy ordering $[4,5]$. Kim et al. [4] have compared different magnetic properties and structures in $\mathrm{GdBaCo}_{2} \mathrm{O}_{5+\delta}$ with different $\delta$. It has been reported that high oxidation states lead to the electronic structure modification, especially to a possible intermediate-spin state stabilization [6]. Theoretical calculation [1] and the experimental results [4] verify the existence of orbital order

*corresponding author; e-mail: d042036@kaiyodai.ac.jp 
state in the intermediate-spin state with the $t_{2 \mathrm{~g}}^{5} e_{\mathrm{g}}^{1}$ configuration. Yan et al. [7] showed that the surface $\mathrm{Co}^{3+}$ ions in $\mathrm{LaCoO}_{3}$ compounds can reconstruct with five oxygen and one $\mathrm{OH}^{-}$ions like $\mathrm{Sr}_{2} \mathrm{CoO}_{3} \mathrm{Cl}$ structure [8] after chemically absorbing the $\mathrm{H}_{2} \mathrm{O}$ in air. It would double the concentration of surface $\mathrm{Co}^{3+}$ ions in a higher spin state without changing the cobalt valence state. The presence of the surface ferromagnetism explains the different magnetic susceptibility in a single crystal of $\mathrm{LaCoO}_{3}$, the powder ground from the same single crystal, and the annealed one at $1000^{\circ} \mathrm{C}$. In the present work, we comparatively study the magnetic properties of $\mathrm{Y}_{0.33} \mathrm{Sr}_{0.67} \mathrm{CoO}_{3-\delta}$ prepared under different sintered temperatures with respect to the above effect.

\section{Experiments}

Polycrystalline samples of $\mathrm{Y}_{0.33} \mathrm{Sr}_{0.67} \mathrm{CoO}_{3-\delta}$ were synthesized from stoichiometric mixtures of $\mathrm{SrCO}_{3}(99.999 \%), \mathrm{Co}_{3} \mathrm{O}_{4}(99.9 \%)$ and $\mathrm{Y}_{2} \mathrm{O}_{3}(99.99 \%)$ by a conventional solid state reaction. The mixtures were ground, pressed into a pellet and calcined at $1100^{\circ} \mathrm{C}$ for $48 \mathrm{~h}$ under the oxygen flow. The product was reground, pressed into a pellet and sintered at $1250^{\circ} \mathrm{C}$ under flowing oxygen for two days until no further reaction was evident by the X-ray powder diffraction. The low temperature samples were calcined at $1000^{\circ} \mathrm{C}$ for $48 \mathrm{~h}$ and sintered at $1100^{\circ} \mathrm{C}$ for $48 \mathrm{~h}$ under the oxygen flow. Room temperature X-ray diffraction measurements were done by the RADII-A diffractometer with $\mathrm{Cu} K_{\alpha}$ radiation and structure refinement to the obtained diffraction data was done by using the Rietveld profile fitting technique [9]. Dc magnetization was measured by Quantum Design SQUID magnetometer in the temperature range of $5-340 \mathrm{~K}$ under the magnetic field of $0-5 \mathrm{~T}$.

The homogeneity and stoichiometry of the prepared samples were analyzed with electron-probe microanalysis (EPMA) and inductively coupled plasma (ICP) spectroscopy. They confirmed that the chemical ratio of Y:Sr:Co is close to the nominal ratio as shown in Table I. The oxygen contents of both samples were determined through iodometric titration [10]. They were $\mathrm{Y}_{0.33} \mathrm{Sr}_{0.67} \mathrm{CoO}_{2.614}$ for the sample sintered at $1250^{\circ} \mathrm{C}$ and $\mathrm{Y}_{0.33} \mathrm{Sr}_{0.67} \mathrm{CoO}_{2.707}$ for that sintered at $1100^{\circ} \mathrm{C}$.

TABLE I

The lattice parameters deduced from the Rietveld refinement results at room temperature for $\mathrm{Y}_{0.33} \mathrm{Sr}_{0.67} \mathrm{CoO}_{3-\delta}$ samples (space group $=I 4 / \mathrm{mmm}$ ) and chemical composition from the inductively coupled plasma and iodometric titration.

\begin{tabular}{c|c|c|c|c|c}
\hline \hline Sample & $a[\AA]$ & $c[\AA]$ & Y:Sr:Co ratio & $3-\delta$ & Co valence \\
\hline $\begin{array}{l}\mathrm{Y}_{0.33} \mathrm{Sr}_{0.67} \mathrm{CoO}_{2.707} \\
\text { sintered at } 1100^{\circ} \mathrm{C}\end{array}$ & $7.617(0)$ & $15.299(1)$ & $0.318: 0.727: 1$ & $2.707(0)$ & 3.006 \\
\hline $\begin{array}{l}\mathrm{Y}_{0.33} \mathrm{Sr}_{0.67} \mathrm{CoO}_{2.614} \\
\text { sintered at } 1250^{\circ} \mathrm{C}\end{array}$ & $7.616(0)$ & $15.274(1)$ & $0.323: 0.672: 1$ & $2.614(3)$ & 2.917 \\
\hline
\end{tabular}


Both compounds are oxygen deficient, which introduce different populations of cobalt ion valences.

\section{Results and discussion}

Powder X-ray diffraction profiles of $\mathrm{Y}_{0.33} \mathrm{Sr}_{0.67} \mathrm{CoO}_{2.614}$ and $\mathrm{Y}_{0.33} \mathrm{Sr}_{0.67} \mathrm{CoO}_{2.707}$ are shown in Fig. 1. Rietveld refinement analysis with a program RIETAN showed that the crystal structures belong to tetragonal structure with a space group of $14 / \mathrm{mmm}$ (No. 139) and that a layered ordering coming from oxygen vacancies exists. The sharp X-ray diffraction peaks of

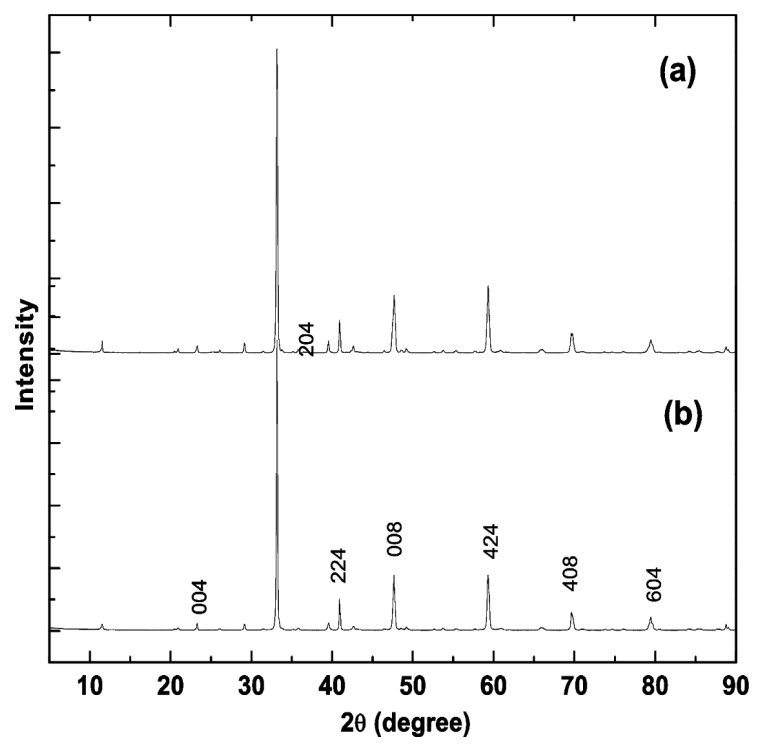

Fig. 1. Powder X-ray diffraction profile collected for $\mathrm{Y}_{0.33} \mathrm{Sr}_{0.67} \mathrm{CoO}_{2.707}$ sintered at $1100^{\circ} \mathrm{C}$ (a) and $\mathrm{Y}_{0.33} \mathrm{Sr}_{0.67} \mathrm{CoO}_{2.614}$ sintered at $1250^{\circ} \mathrm{C}$ (b) at room temperature.

high-temperature sintered $\mathrm{Y}_{0.33} \mathrm{Sr}_{0.67} \mathrm{CoO}_{2.614}$ account for the existence of the relatively large sized particles. The lattice parameters of both $\mathrm{Y}_{0.33} \mathrm{Sr}_{0.67} \mathrm{CoO}_{2.614}$ and $\mathrm{Y}_{0.33} \mathrm{Sr}_{0.67} \mathrm{CoO}_{2.707}$ are shown in Table I. Two kinds of $\mathrm{Co}-\mathrm{O}$ clusters formed as the layer structure with $\mathrm{CoO}_{6}$ octahedron and $\mathrm{CoO}_{4}$ tetrahedral polyhedron in alternate order were successfully refined, which is consistent with the previous reports $[3,11]$, as shown in Table II. The average bond length of the low-temperature sintered $\mathrm{Y}_{0.33} \mathrm{Sr}_{0.67} \mathrm{CoO}_{2.707}$ is longer than that in the high-temperature sintered $\mathrm{Y}_{0.33} \mathrm{Sr}_{0.67} \mathrm{CoO}_{2.614}$, which may be related to a decrease in magnetization [5] and a substantial structure distortion. Table I shows that $\mathrm{Y}: \mathrm{Sr}$ :Co ratio in both samples is almost close to the nominal proportions. It is clear that the magnetization difference between both samples does not come from the non-stoichiometry of cations. According to the chemical composition 
TABLE II

Selected interatomic distances between Co and $\mathrm{O}$ ions for $\mathrm{Y}_{0.33} \mathrm{Sr}_{0.67} \mathrm{CoO}_{3-\delta}$.

\begin{tabular}{c|c|c|c|c}
\hline \hline Distance $[\AA]$ & $\begin{array}{c}\mathrm{Y}_{0.33} \mathrm{Sr}_{0.67} \mathrm{CoO}_{2.707} \\
\text { sintered at } 110{ }^{\circ} \mathrm{C}\end{array}$ & Average & $\begin{array}{c}\mathrm{Y}_{0.33} \mathrm{Sr}_{0.67} \mathrm{CoO}_{2.614} \\
\text { sintered at } 1250{ }^{\circ} \mathrm{C}\end{array}$ & Average \\
\hline \multicolumn{5}{c}{ Tetrahedron } \\
\hline $\mathrm{Co1-O} 1 \times 2)$ & $1.840(7)$ & & $1.857(7)$ & $1.961(12)$ \\
$\mathrm{Co} 1-\mathrm{O} 2(\times 2)$ & $2.043(20)$ & 1.921 & $1.921(5)$ & 1.913 \\
$\mathrm{Co} 1-\mathrm{O} 3(\times 2)$ & $1.925(5)$ & & 1.983 \\
\hline \multicolumn{5}{c}{ Octahedron } \\
\hline $\mathrm{Co} 2-\mathrm{O} 1(\times 1)$ & $2.070(7)$ & 1.990 & $2.057(8)$ & $1.909(0)$ \\
$\mathrm{Co} 2-\mathrm{O} 4(\times 4)$ & $1.910(1)$ & &
\end{tabular}

from the ICP results and iodometic titration, we found there are 91.7 percent of $\mathrm{Co}^{3+}$ ions and 8.3 percent of $\mathrm{Co}^{2+}$ ions in the high-temperature sintered $\mathrm{Y}_{0.33} \mathrm{Sr}_{0.67} \mathrm{CoO}_{2.614}$. For the low-temperature sintered $\mathrm{Y}_{0.33} \mathrm{Sr}_{0.67} \mathrm{CoO}_{2.707}$, there exist a few $\mathrm{Co}^{4+}$ ions and 99.4 percent $\mathrm{Co}^{3+}$ ions. There is large distortion in the low-temperature sintered sample due to only a few $\mathrm{Co}^{4+}$ existences. Compared with the experimental results $[11,12]$, the $\mathrm{Co}^{3+}$ ions in the octahedral structure should occupy $\mathrm{Co} 1$ site; the $\mathrm{Co}^{2+} / \mathrm{Co}^{4+}$ ions and a part of $\mathrm{Co}^{3+}$ ions should occupy the $\mathrm{Co} 2$ site. Obviously, $\mathrm{Co}^{3+}$ ions in both samples result in different magnetic properties [12]. The different oxygen content leads to a variety of magnetic properties in both samples [13].

Figure 2 shows the temperature dependence of dc magnetization of $\mathrm{Y}_{0.33} \mathrm{Sr}_{0.67} \mathrm{CoO}_{2.614}$ and $\mathrm{Y}_{0.33} \mathrm{Sr}_{0.67} \mathrm{CoO}_{2.707}$ under an applied field of $0.01 \mathrm{~T}$. There is a magnetization jump $\left(T_{\mathrm{J}}\right)$ around $180 \mathrm{~K}$ with a thermal hysteresis in high-temperature sintered $\mathrm{Y}_{0.33} \mathrm{Sr}_{0.67} \mathrm{CoO}_{2.614}$ and the magnetization continuously returns to the high temperature without any discontinuity after the jump of magnetization during the field cooling. This result indicates a kind of magnetic memory effect. With increasing temperature, another magnetic transition with the Curie temperature $T_{\mathrm{C}}$ is found at $304 \mathrm{~K}$. The magnetization jump remains and $T_{\mathrm{J}}$ shifts to a lower temperature $164 \mathrm{~K}$ under $1 \mathrm{~T}$ as shown in Fig. 3. We interpret that the observed magnetization jump does not originate from the domain structure. In Fig. 2, the magnetization comes from the ferromagnetism by the orbital ordering in $\mathrm{Co}^{3+}$ ions and the magnetization jump results from the spin state transition in the $\mathrm{Co}^{3+}$ octahedral site from the intermediate to low spin state. The competition between ferromagnetic and antiferromagnetic exchange interaction of the orbital ordering state leads to the $T_{\mathrm{C}}$ appearance $[12,14]$. The low-temperature prepared $\mathrm{Y}_{0.33} \mathrm{Sr}_{0.67} \mathrm{CoO}_{2.707}$ exhibits a larger ferromagnetism and lower $T_{\mathrm{C}}$ about $294 \mathrm{~K}$ than those of the high-temperature prepared $\mathrm{Y}_{0.33} \mathrm{Sr}_{0.67} \mathrm{CoO}_{2.614}$ in the whole temperature range. In low temperatures, the magnetization at $5 \mathrm{~K}$ under $0.01 \mathrm{~T}$ in $\mathrm{Y}_{0.33} \mathrm{Sr}_{0.67} \mathrm{CoO}_{2.707}$ is about 10 times larger than that in $\mathrm{Y}_{0.33} \mathrm{Sr}_{0.67} \mathrm{CoO}_{2.614}$. 


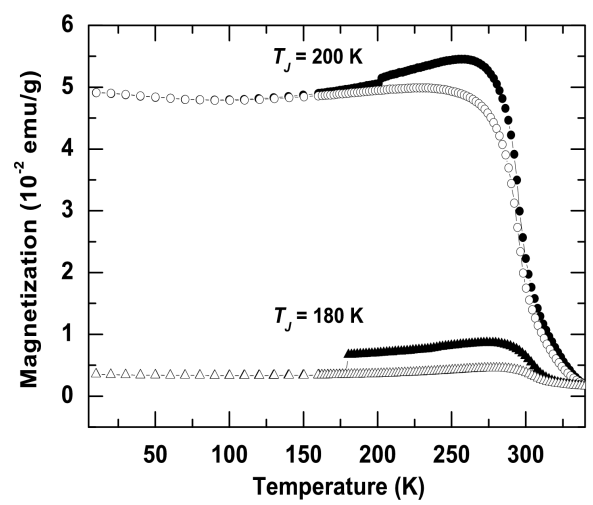

Fig. 2. Dc magnetization as a function of temperature for $\mathrm{Y}_{0.33} \mathrm{Sr}_{0.67} \mathrm{CoO}_{2.707}$ sintered at $1100^{\circ} \mathrm{C}$ (circles) and $\mathrm{Y}_{0.33} \mathrm{Sr}_{0.67} \mathrm{CoO}_{2.614}$ sintered at $1250^{\circ} \mathrm{C}$ (triangles) under a magnetic field of $0.01 \mathrm{~T}$. The field cooling curves are shown as the solid symbols, whereas the field warming curves are shown as the open symbols.

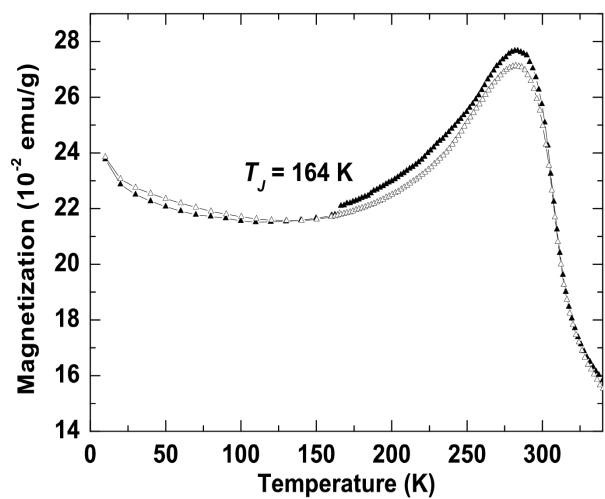

Fig. 3. Dc magnetization as a function of temperature for $\mathrm{Y}_{0.33} \mathrm{Sr}_{0.67} \mathrm{CoO}_{2.614}$ sintered at $1250^{\circ} \mathrm{C}$ under a magnetic field of $1 \mathrm{~T}$. The solid and open symbols correspond to the field cooling and warming curves, respectively.

There exists a smaller magnetization jump at $200 \mathrm{~K}$ upon the field cooling. Then, the magnetization returns to the high temperature continuously.

Referring to the bond distance as shown in Table I, the longer bond distance in $\mathrm{Y}_{0.33} \mathrm{Sr}_{0.67} \mathrm{CoO}_{2.707}$ may lead to the smaller magnetization [5]. Considering the $\mathrm{Co}^{3+}$ ion content in both samples, rich $\mathrm{Co}^{3+}$ ions in the low-temperature sintered $\mathrm{Y}_{0.33} \mathrm{Sr}_{0.67} \mathrm{CoO}_{2.707}$ may induce a larger magnetization, and high oxygen stoichiometry weakens the intermediate state of $\mathrm{Co}^{3+}$ ions so as to increase the $T_{\mathrm{J}}$ [12]. It is difficult to account for about 10 times larger magnetization and low $T_{\mathrm{C}}$ in $\mathrm{Y}_{0.33} \mathrm{Sr}_{0.67} \mathrm{CoO}_{2.707}$ with only about $8 \%$ discrepancies of $\mathrm{Co}^{3+}$ ions between both samples. It has been observed that a change of $\mathrm{La} / \mathrm{Co}$ ratio due to the evaporation of $\mathrm{Co}$ ions in $\mathrm{LaCoO}_{3}$ when firing at high temperature affects 
the low-temperature magnetic susceptibility [15]. However, the ICP results show that both samples are similar cation composition as Y:Sr:Co to the experimental stoichiometry. Recently, Yan et al. [7] found that low-temperature magnetic susceptibility is composed of three contributions: a Curie-Weiss paramagnetism, a thermally driven spin-state transition, and a surface-related ferromagnetism. The surface $\mathrm{Co}^{3+}$ ion in $\mathrm{LaCoO}_{3}$ compounds can reconstruct with five oxygen and one $\mathrm{OH}^{-}$ions like $\mathrm{Sr}_{2} \mathrm{CoO}_{3} \mathrm{Cl}$ structure [8] after chemically absorbing the $\mathrm{H}_{2} \mathrm{O}$ in air, which would double the concentration of surface $\mathrm{Co}^{3+}$ ions in a higher spin state without changing the cobalt valence state. During the sample preparation, we found the reduction of the sample size and high dense with black and gray color for the high-temperature sintered $\mathrm{Y}_{0.33} \mathrm{Sr}_{0.67} \mathrm{CoO}_{2.614}$, almost similar size with black color for the low-temperature sintered $\mathrm{Y}_{0.33} \mathrm{Sr}_{0.67} \mathrm{CoO}_{2.707}$. The existence of large grains has to be focused in the high-temperature sintered $\mathrm{Y}_{0.33} \mathrm{Sr}_{0.67} \mathrm{CoO}_{2.614}$. The observed large magnetization may partly come from the contribution of the $\mathrm{Co}^{3+}$ ions surface/volume ferromagnetism.
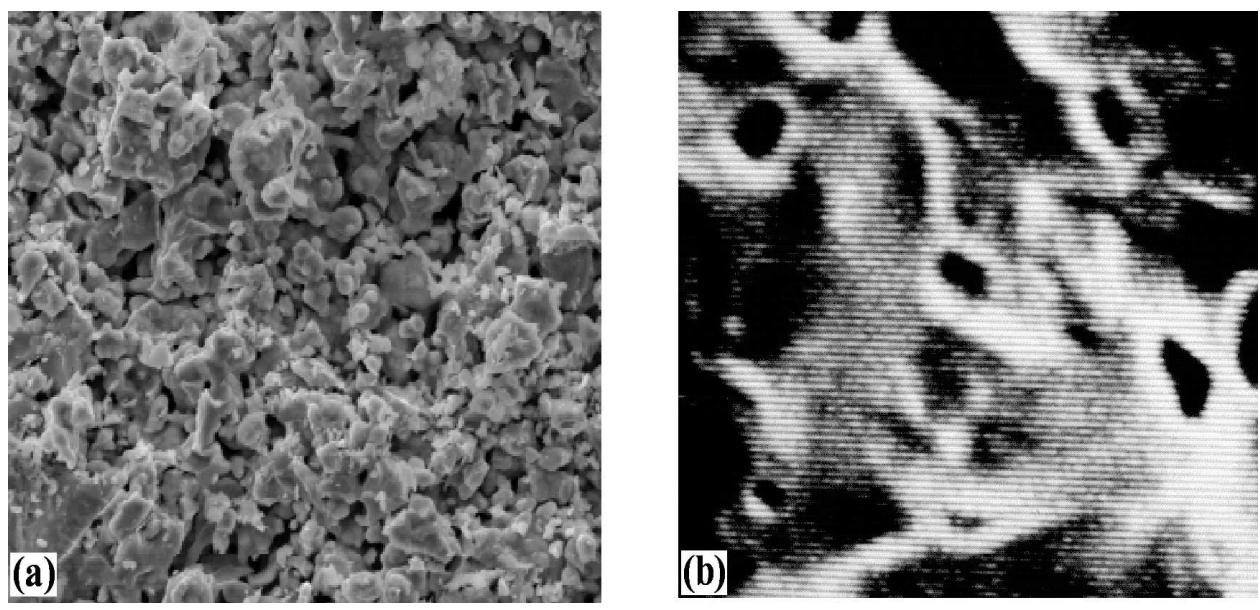

Fig. 4. Scanning electron microphotograph of low-temperature sintered $\mathrm{Y}_{0.33} \mathrm{Sr}_{0.67} \mathrm{CoO}_{2.707}$ at $1200 \times$ (a) and high-temperature sintered $\mathrm{Y}_{0.33} \mathrm{Sr}_{0.67} \mathrm{CoO}_{2.614}$ at $1000 \times(b)$.

To verify the present interpretation, the scanning electron microphotographs (SEM) of both samples were taken and compared as shown in Fig. 4. Many individual microparticles were found in the low-temperature sintered $\mathrm{Y}_{0.33} \mathrm{Sr}_{0.67} \mathrm{CoO}_{2.707}$ (Fig. 4a) and grain connectivity was observed in the high-temperature sintered $\mathrm{Y}_{0.33} \mathrm{Sr}_{0.67} \mathrm{CoO}_{2.614}$ (Fig. 4b), which is consistent with the X-ray results. We clearly find the reduction of the surface/volume ratio in the high-temperature sintered $\mathrm{Y}_{0.33} \mathrm{Sr}_{0.67} \mathrm{CoO}_{2.614}$. Due to the lower grain connectivity, the high surface/volume ratio of $\mathrm{Co}^{3+}$ ions in the low-temperature sintered $\mathrm{Y}_{0.33} \mathrm{Sr}_{0.67} \mathrm{CoO}_{2.707}$ partly contributes the higher magnetization and induces the lower $T_{\mathrm{C}}$. The compe- 
tition between the crystal field splitting energy $E_{\mathrm{c}}$ and the Hund exchange energy $E_{\text {ex }}$ determined the spin state in $\mathrm{LaCoO}_{3}$. In the bulk, $E_{\mathrm{c}}$ near to $E_{\text {ex }}$ would stabilize the low-spin state to weaken the ferromagnetism in the high-temperature sintered $\mathrm{Y}_{0.33} \mathrm{Sr}_{0.67} \mathrm{CoO}_{2.614}$.

Zero-field cooled magnetizations as a function of temperature for both $\mathrm{Y}_{0.33} \mathrm{Sr}_{0.67} \mathrm{CoO}_{2.707}$ and $\mathrm{Y}_{0.33} \mathrm{Sr}_{0.67} \mathrm{CoO}_{2.614}$ under $0.01 \mathrm{~T}$ are shown in Fig. 5 . There is a cusp at about $304 \mathrm{~K}$ in $\mathrm{Y}_{0.33} \mathrm{Sr}_{0.67} \mathrm{CoO}_{2.614}$ and $301 \mathrm{~K}$ in $\mathrm{Y}_{0.33} \mathrm{Sr}_{0.67} \mathrm{CoO}_{2.707}$, which is near $T_{\mathrm{C}}$. The competition of $\mathrm{Co}^{3+}$ ferromagnetic

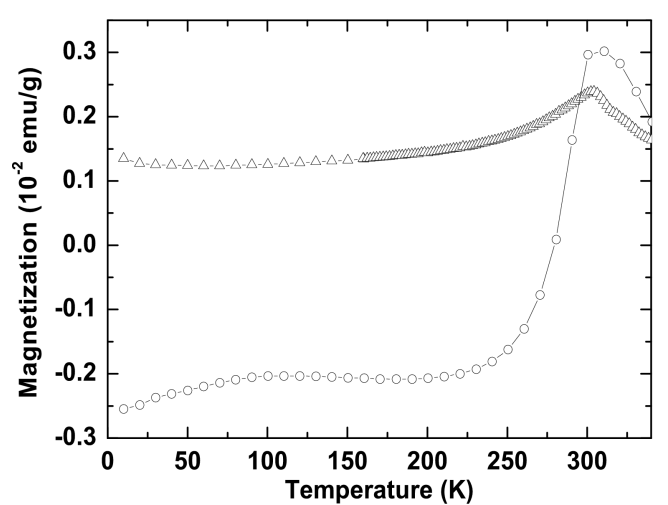

Fig. 5. Zero-field cooled magnetization as a function of temperature for low-temperature sintered $\mathrm{Y}_{0.33} \mathrm{Sr}_{0.67} \mathrm{CoO}_{2.707}$ (circles) and high-temperature sintered $\mathrm{Y}_{0.33} \mathrm{Sr}_{0.67} \mathrm{CoO}_{2.614}$ (triangles) at $0.01 \mathrm{~T}$.

interaction and antiferromagnetic superexchange interaction results in the appearance of the cusp around $T_{\mathrm{C}}$. In low temperature, $\mathrm{Y}_{0.33} \mathrm{Sr}_{0.67} \mathrm{CoO}_{2.707}$ exhibits the lower magnetization, which may be one evidence that the high oxygen content weakens the intermediate-spin state of $\mathrm{Co}^{3+}$ ions and stabilizes the low-spin state.

\section{Conclusions}

The magnetic properties of $\mathrm{Y}_{0.33} \mathrm{Sr}_{0.67} \mathrm{CoO}_{3-\delta}$ prepared under different sintered temperatures were comparatively studied. The presence of localized spin on the surface/volume of $\mathrm{Y}_{0.33} \mathrm{Sr}_{0.67} \mathrm{CoO}_{3-\delta}$ and the ferromagnetism results in the different $T_{\mathrm{C}}$ and magnetization. The high oxygen content in the low-temperature prepared $\mathrm{Y}_{0.33} \mathrm{Sr}_{0.67} \mathrm{CoO}_{2.707}$ is related to the rich $\mathrm{Co}^{3+}$ ions from a surface/volume effect of $\mathrm{Co}^{3+}$ ions appearing in the polycrystalline samples, which mainly induces the higher magnetization and weakens the intermediate-spin state to decrease the $T_{\mathrm{J}}$. 


\section{Acknowledgments}

The authors would like to thank F. Sakai and Y. Kiuchi (ISSP, Japan), M. Tanaka-Takahashi and students (TUMSAT) for oxygen content measurement, A. Yamamoto (RIKEN, Japan) for valuable advice to the result discussions.

\section{References}

[1] M.A. Korotin, S.Yu. Ezhov, I.V. Solovyev, V.I. Anisimov, Phys. Rev. B 54, 5309 (1996).

[2] J. Wu, C. Leighton, Phys. Rev. B 67, 174408 (2003).

[3] R.L. Withers, M. James, D.J. Grossens, J. Solid State Chem. 174, 198 (2003).

[4] W.S. Kim, E.O. Chi, H.S. Choi, N.H. Hur, S.-J. Oh, H.-C. Ri, Solid State Commun. 116, 609 (2000).

[5] S. Roy, M. Khan, Y.Q. Guo, J. Craig, N. Ali, Phys. Rev. B 65, 064437 (2005).

[6] R.H. Potze, G.A. Sawatzky, M. Abbate, Phys. Rev. B 51, 11501 (1995).

[7] J.-Q. Yan, J.-S. Zhou, J.B. Goodenough, Phys. Rev. B 70, 014402 (2004).

[8] S.M. Loreiro, C. Felser, Q. Huang, R.J. Cava, Chem. Mater. 12, 3181 (2000).

[9] F. Izumi, T. Ikeda, Mater. Sci. Forum 198, 321 (2000).

[10] M. Karppinen, M. Matvejeff, K. Salomäki, H. Yamauchi, J. Mater. Chem. 12, 1761 (2002).

[11] S.Ya. Istomin, J. Grins, G. Svensson, O.A. Drozhzhin, E.L. Kozhevnikov, E.V. Antipov, J.P. Attfield, Chem. Mater. 15, 4012 (2003).

[12] Y.F. Zhang, S. Sasaki, T. Odagiri, M. Izumi, Phys. Rev. B 74, 214429 (2006)

[13] D.J. Goossens, K.F. Wilson, M. James, A.J. Studer, X.L. Wang, Phys. Rev. B 69, 134411 (2004).

[14] Y.F. Zhang, S. Sasaki, O. Yanagisawa, M. Izumi, J. Magn. Magn. Mater., in print.

[15] P.M. Raccah, J.B. Goodenough, Phys. Rev. 155, 932 (1967). 